\title{
Análise do Monitoramento do Índice Municipal de Alerta (IMA) no Estado do Ceará: Avanços e Desafios dos Municípios no Período de 2004 a 2010
}

Analysis of the Monitoring of Municipal Index Alert (IMA) in State of Ceara: Advances and Challenges of Municipalities in the Period 2004-2010

Cleyber Nascimento de Medeiros', Daniel Dantas Moreira Gomes², Emanuel Lindemberg Silva Albuquerque ${ }^{3}$

' Analista de Políticas Públicas, Instituto de Pesquisa e Estratégia Econômica do Ceará, Fortaleza, Brasil.

2 Professor Assistente do curso de Geografia, Universidade de Pernambuco, Garanhuns, Brasil.

${ }_{3}^{3}$ Doutorando do Programa de Pós-Graduação em Geografia, Universidade Estadual do Ceará, Fortaleza, Brasil.

\section{Resumo}

O presente estudo visa realizar o monitoramento do Índice Municipal de Alerta (IMA) no período compreendido entre os anos de 2004 a 2010, objetivando colaborar para os avanços e desafios dos municípios frente às orientações preventivas sobre as adversidades climáticas no contexto do semiárido no Estado do Ceará, tendo como base de análise e reflexão o relatório publicado anualmente pelo IPECE. Verificou-se que os municípios de Independência, Madalena, Penaforte e Tauá sempre estiveram na classe de alta vulnerabilidade. Estes municípios possuem como característica principal possuírem baixos índices pluviométricos, sendo também vulneráveis no tocante à produção agrícola.

Palavras-chave: Índice Municipal de Alerta, Adversidades Climáticas, Estado do Ceará.

\begin{abstract}
The present study aims at monitoring the Municipal Index Alert (IMA) in the period between the years 2004 to 2010, aiming to contribute to the progress and challenges municipalities face of adversity on preventive guidelines in the context of semi-arid climate in the State of Ceará, based on analysis and reflection report published annually by IPECE. It was found that the cities of Independência, Madalena, Penaforte e Tauá have always been in the class of high vulnerability. These municipalities have as main characteristic having low rainfall, is also vulnerable with respect to agricultural production.
\end{abstract}

Keywords: Municipal Index Alert, Climate Adversities, State of Ceará. 


\section{INTRODUÇÃO}

Antes de qualquer argumentação que leve em consideração as relações historicamente construídas dentro do contexto semiárido brasileiro, destaca-se que o Estado do Ceará tem aproximadamente $92 \%$ do seu território submetido à influência da semi-aridez, a qual é caracterizada por altas taxas de evaporação/evapotranspiração e baixos níveis pluviométricos, marcadas principalmente pelo alto grau de incerteza têmporo-espacial.

Parafraseando Leite et al., (2003), o Estado do Ceará está sob perigoso processo de desertificação, existindo um número considerável de municípios afetados pelo fenômeno o que pode vir a afetar a qualidade de vida das populações aí residentes. Assim como a desertificação pode ser um estímulo à pobreza em uma região, diminuindo a possibilidade de geração de emprego e renda, pode ser, também, uma conseqüência - efeito retro-alimentador (feedback).

Para o Programa de Ação Estadual de Combate à Desertificação - PAE (2010, p.56), a geologia e as mudanças climáticas são causas naturais de um processo de desertificação, mas é consenso que a pobreza acelera o fenômeno, principalmente em ambientes fragilizados como a zona rural do Ceará, inserida em sua maior parte no semiárido nordestino.

Vale salientar que desde os primórdios da colonização, especialmente a partir do século XVIII, as características florísticas e faunistas dos sistemas ambientais do semi-árido vêm sendo afetadas pelas ações predatórias do homem na busca da sobrevivência ou pelo objetivo de acumular capital financeiro.

Dessa forma, constata-se que, além das vulnerabilidades impostas pela irregularidade pluviométrica do semi-árido, parte muito significativa dos solos apresentam-se degradada ou em estágios avançados de desertificação, representando um desafio quanto à preservação de seus recursos naturais (FRANÇA et al., 2002).

Nesse sentido, os sistemas ambientais não têm merecido a devida atenção, frente à ameaça da ocupação humana para a sobrevivência da biodiversidade, conduzindo a processos de desertificação e/ou condições extremas de degradação ambiental, às vezes irreversíveis, agravadas pelo atual cenário de mudanças climáticas a nível global.

Nesse contexto, o Índice Municipal de Alerta - IMA, calculado pelo Instituto de Pesquisa e Estratégia Econômica do Ceará - IPECE desde o ano de 2004, consiste em um importante indicador de vulnerabilidade dos municípios cearenses no que tange às questões agrícolas e climatológicas. São disponibilizados indicadores que incorporam informações concernentes às áreas de meteorologia, recursos hídricos e produção agrícola para o Estado do Ceará, levando em consideração a interface da relação sociedade e natureza.

O objetivo do IMA é divulgar informações que contribuam na eficiência do atendimento das populações afetadas pelos problemas climáticos em um momento em que suas conseqüências ainda sejam controláveis. Representa parte de um conjunto de mecanismos para tornar as ações do Governo do Estado mais ágeis, almejando minimizar as vulnerabilidades das populações rurais dos municípios no momento em que as crises se manifestam com maior freqüência e com mais intensidade.

Assim, o objetivo deste trabalho é realizar o monitoramento dos municípios cearenses em relação a vulnerabilidade aos fatores climáticos e agrícolas ao longo do tempo (2004 - 2010), analisando os municípios mais e menos vulneráveis, bem como os municípios que regrediram e/ou progrediram em relação aos seus graus de vulnerabilidades.

\section{MATERIAL E MÉTODOS}

Por ser o IMA uma metodologia de trabalho desenvolvido e efetivado pelo IPECE em parcerias com outros Órgãos Públicos, não há necessidade de descrever as etapas para se alcançar os resultados do Relatório publicado anualmente pelo mencionado Órgão. Mas vale dar ênfase a esse importante instrumento como de extrema importância para as orientações preventivas sobre as adversidades climáticas no Estado do Ceará.

De acordo com o IPECE (2010), o IMA é calculado para os 184 municípios do Estado do Ceará a partir de um conjunto de 12 indicadores selecionados, os quais refletem a vulnerabilidade dos municípios no que diz respeito aos aspectos agrícolas e climatológicos, pertinentes às áreas de meteorologia, recursos hídricos e produção agrícola, discriminados a seguir: 
Produtividade agrícola por hectare - estimativa do valor da produção agrícola dividida pela estimativa de área colhida;

II. Produção agrícola por habitante - estimativa do valor da produção agrícola dividida pela população total estimada do município;

III. Utilização da área colhida com culturas de subsistência - percentual da área colhida com culturas de subsistência em relação ao total de área colhida no município. Como culturas de subsistência são consideradas: milho, feijão, arroz, mandioca e algodão de sequeiro;

IV. Perda de safra - média percentual das perdas verificadas na produção de grãos no município;

V. Proporção de famílias beneficiadas com bolsa-família - percentual de famílias que receberam bolsa-família em relação ao total de famílias inscritas no cadastro único;

VI. Número de vagas do Seguro Safra por 100 habitantes rurais - número de vagas do seguro safra destinadas ao município para cada grupo de 100 habitantes rurais;

VII. Climatologia - Média de precipitação pluviométrica dos municípios nos últimos 30 anos;

VIII. Desvio normalizado das chuvas - variação percentual entre a precipitação observada e a normal (média de 30 anos) do município no período analisado;

IX. Escoamento superficial - volume de escoamento de água ocorrido no limite de absorção do solo, medido com base nas precipitações ocorridas, no máximo de absorção de cada solo, levando-se em consideração uma evapotranspiração de $5 \mathrm{~mm} /$ dia, cujo fluxo hídrico é classificado em três intervalos: $1^{\circ}$. de 0 a $59 \mathrm{~mm}$ (crítico) / $2^{\circ}$. de 60 a $179 \mathrm{~mm}$ (regular) / $3^{\circ}$. de $180 \mathrm{~mm}$ acima (bom).

$X$. Índice de Distribuição de Chuvas - associa as variações volumétricas temporais e espaciais de chuva, levando-se em consideração o período escolhido para análise. Os resultados deste índice são classificados em quatro categorias: $1^{\circ}$. de 0,000 a 0,100 (crítica) / $2^{\circ}$. de 0,101 a 0,200 (regular) / $3^{\circ}$. de 0,201 a 0,300 (bom) / $4^{\circ}$. de 0,301 a 1,000 (ótimo).

XI. Índice de Aridez - é a precipitação histórica de um determinado ponto dividido pela evapotranspiração potencial (máximo de evaporação que se pode ter em um determinado ponto). Valores acima de 1 ocorrem para a precipitação histórica superior à evapotranspiração potencial, indicando menor grau de aridez. Assim quanto menor o índice mais árido é a região;

XII. Taxa de cobertura de abastecimento urbano de água - proporção da população urbana com abastecimento de água.

Após a elaboração do índice, os municípios são classificados dentro de quatro classes de vulnerabilidade baseadas na média e na variabilidade (desvio padrão) do indicador do IMA. Dessa forma, são aplicadas as seguintes classes de vulnerabilidade para cada município:

Classe 1 - alta vulnerabilidade: para valores superiores ao índice médio somado ao valor do desvio padrão;

II. Classe 2 - média-alta vulnerabilidade: para valores maiores que o valor médio e menores que a média mais o valor do desvio padrão;

III. Classe 3 - média-baixa vulnerabilidade: para valores inferiores à media e superiores à média menos o desvio padrão;

IV. Classe 4 - baixa vulnerabilidade: para índices com valores inferiores à média menos o desvio padrão.

Para a análise do IMA ao longo do tempo, realizou-se a espacialização das informações com o emprego de técnicas e ferramentas de geoprocessamento, trabalhando os municípios cearenses para o período de 2004 a 2010 de acordo com dados colhidos dos relatórios do IMA. As técnicas adotadas na pesquisa são resultantes do avanço das tecnologias dos Sistemas de Informações Geográficas - SIG.

Desse modo, de acordo com Florenzano (2007), pode-se delinear que,

O Sistema de Informação Geográfica - SIG é um sistema computacional que permite armazenar e integrar informações geográficas de diferentes fontes e escalas. As informações no SIG devem ser georreferenciadas, ou seja, com localização geográfica definida por coordenadas [...] (FLORENZANO, 2007, p.38).

Em virtude de sua aplicabilidade, o Sistema de Informação Geográfica (SIG) é uma importante ferramenta que possibilita melhor análise visual e numérica das evoluções e digressões de algumas variáveis, integrando em um único banco de dados informações numéricas e espaciais.

O termo Sistema de Informações Geográficas (SIG) ou seu equivalente em inglês, Geographic Information System (GIS), é utilizado para descrever sistemas computacionais que utilizam dados que contenham referencias geográficas. 
Um SIG é constituído por um conjunto de "ferramentas" especializadas em adquirir, armazenar, recuperar, transformar e emitir informações espaciais. Esses dados geográficos descrevem objetos do mundo real em termos de posicionamento, com relação a um sistema de coordenadas, seus atributos não aparentes (como a cor, $\mathrm{pH}$, custo, incidência de pragas, etc.) e das relações topológicas existentes (BURROUGH, 1987).

Portanto, conforme Medeiros et al., (2013), um SIG pode ser utilizado em estudos relativos ao meio físico e socioeconômico, na pesquisa da previsão de determinados fenômenos ou no apoio a decisões de planejamento, considerando a concepção de que os dados armazenados representam um modelo do mundo real.

Vale corroborar que as informações utilizadas para a análise do monitoramento do IMA, levando em consideração os avanços e desafios dos municípios cearenses no período de 2004 a 2010, foram obtidas diretamente por download no site do IPECE (http://www.ipece.ce.gov.br/categoria4/ima).

\section{I PROCEDIMENTO OPERACIONAL}

Procedeu-se inicialmente o levantamento e triagem dos documentos que continham os dados relativos ao IMA dos anos de 2004 a 2010, tendo em vista que o presente estudo objetiva realizar uma análise da dinâmica do índice ao longo do tempo, a fim de conhecer quais municípios do Estado do Ceará avançaram e/ou regrediram com relação aos indicadores utilizados, propondo assim uma reflexão mais aprofundada sobre os principais desafios.

De posse da base de dados para os anos de 2004, 2005, 2006, 2007, 2008, 2009 e 2010, a mesma foi inserida em ambiente de Sistema de Informações Geográficas (SIG), vinculando a referida base de dados à base georreferenciada de limites municipais do Estado do Ceará, almejando trabalhar com mapas temáticos, realizar sobreposições de mapas, seleção por atributos, entre outras ferramentas de análise espacial. Para tanto, foi utilizado o software Arcview GIS 9.3®.

A aplicação das informações do IMA foi realizada por município, utilizando como base georreferenciada o Limite Municipal Oficial do Estado do Ceará adotado pelo IPECE, registrado no sistema de Projeção UTM, Zona 24 Sul e Datum SAD 69. Destaca-se que todo o trabalho laboratorial foi desenvolvido em conjunto pela Gerência de Estatística, Geografia e Informação - GEGIN do IPECE e no Laboratório de Geografia Física e Estudos Ambientais - LAGEO da Universidade Estadual do Ceará - UECE.

\section{RESULTADOS E DISCUSSÕES}

Após a tabulação e inserção dos dados em ambiente de Sistemas de Informações Geográficas (SIG) foi possível elaborar os mapas temáticos e analisar o comportamento dos municípios de acordo com os anos estudados. A seguir, apresenta-se a análise do indicador do IMA para cada ano individualmente e em seguida efetua-se a análise da evolução temporal do grau de vulnerabilidade para cada município cearense.

\section{I ÍNDICE MUNICIPAL DE ALERTA - IMA 2004}

No ano de 2004, de acordo com a Figura 1, constatou-se que 25 municípios encontravam-se na classe de Alta Vulnerabilidade do IMA, os quais estão localizados predominantemente nas Macrorregiões de Planejamento do Sertão Central, Sertões dos Inhamuns, Cariri/Centro Sul e Sobral-Ibiapaba. Os cinco municípios que apresentaram os maiores valores do IMA em 2004 foram: Irauçuba $(0,79)$, Saboeiro $(0,77)$, Independência $(0,77)$, Caridade $(0,77)$ e Tauá $(0,76)$. Já os cinco municípios menos vulneráveis aos fatores climatológicos e agrícolas no citado ano foram: Ibiapina $(0,30)$, Guaramiranga $(0,40)$, São Benedito $(0,40)$, Fortaleza $(0,44)$ e Pacoti $(0,45)$.

\section{2 ÍNDICE MUNICIPAL DE ALERTA - IMA 2005}

No ano de 2005, como mostra a Figura 2, constatou-se que 48 municípios encontravam-se na classe de Alta Vulnerabilidade do IMA, os quais estão localizados predominantemente nas Macrorregiões de Planejamento dos Sertões dos Inhamuns, Sertão Central, Sobral-Ibiapaba e Cariri/Centro Sul. Os cinco municípios que apresentaram os maiores valores do IMA em 2005 foram: Irauçuba $(0,860)$, Penaforte $(0,832)$, Madalena $(0,831)$, Arneiroz $(0,812)$ e Mauriti $(0,796)$. Já os cinco muni- 


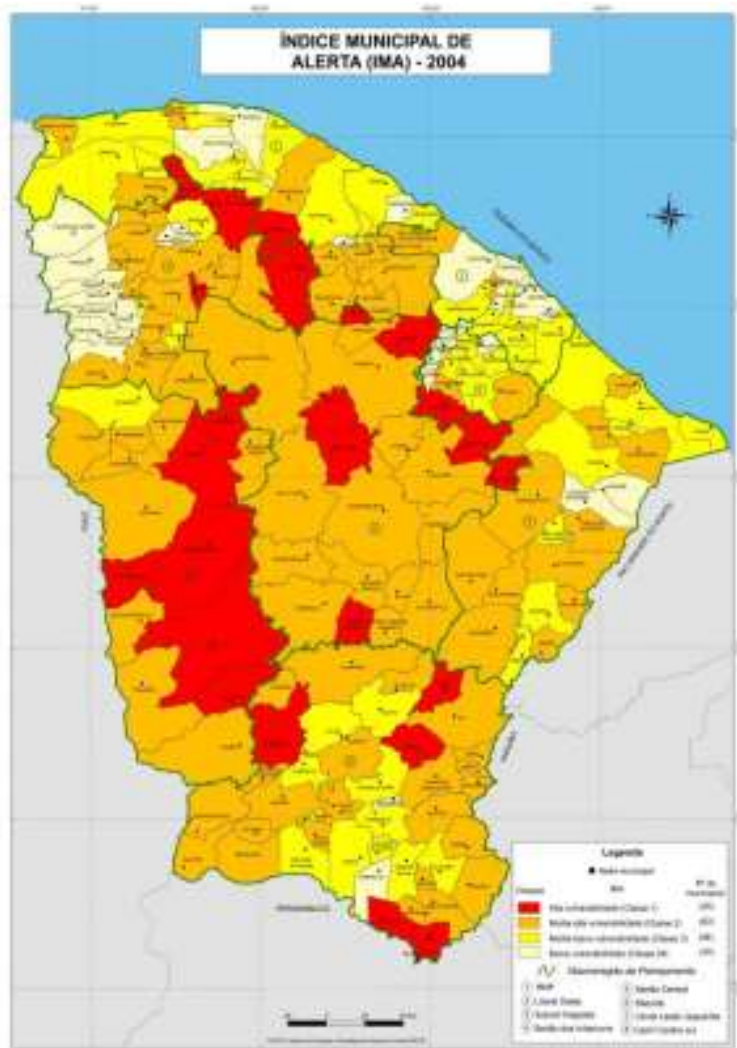

Figura 1. Índice Municipal de Alerta (IMA) - 2004. Fonte: IPECE (IMA - 2004).

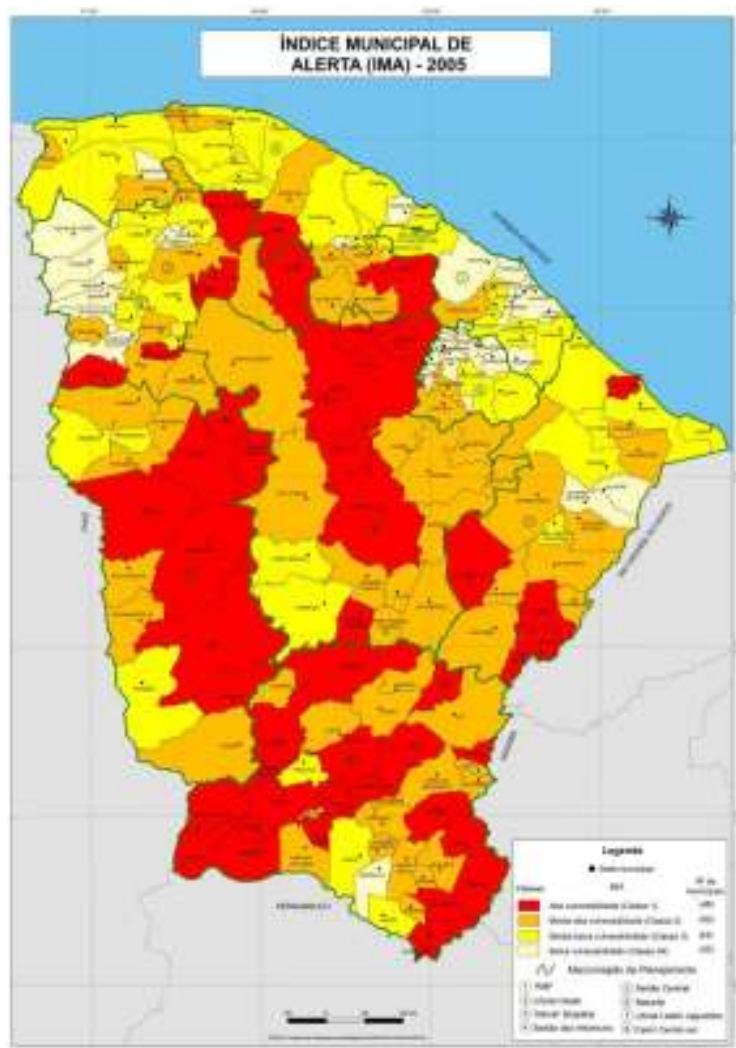

Figura 2. Índice Municipal de Alerta (IMA) - 2005. Fonte: IPECE (IMA - 2005)

cípios menos vulneráveis aos fatores climatológicos e agrícolas no citado ano foram: Guaramiranga $(0,368)$, Pacoti $(0,385)$, Ibiapina $(0,402)$, Aratuba $(0,417)$ e Palmácia $(0,439)$.

Em relação ao ano de 2004, constatou-se que 47 municípios apresentaram piora na classificação do IMA, ou seja, foram classificados em uma classe de maior vulnerabilidade em 2005 . Em contrapartida, 27 municípios registraram uma situação melhor do que a classificação de 2004, evidenciando uma redução da vulnerabilidade aos indicadores adotados.

\section{3 ÍNDICE MUNICIPAL DE ALERTA - IMA 2006}

No ano de 2006, conforme a Figura 3, constatou-se que 25 municípios encontravam-se na classe de Alta Vulnerabilidade do IMA, os quais estão localizados predominantemente na Macrorregião de Planejamento dos Sertões dos Inhamuns. Os cinco municípios que apresentaram os maiores valores do IMA em 2006 foram: Santana do Acaraú $(0,777)$, Catarina $(0,772)$, Catunda $(0,759)$, Itatira $(0,744)$ e Arneiroz $(0,737)$. Já os cinco municípios menos vulneráveis aos fatores climatológicos e agrícolas no citado ano foram: Ibiapina $(0,299)$, Pindoretama $(0,371)$, Guaramiranga $(0,392)$, Meruoca $(0,395)$ e Aratuba (0,398).

Comparativamente ao ano de 2005, constatou-se que 29 municípios apresentaram piora na classificação do IMA, ou seja, foram classificados em uma classe de maior vulnerabilidade em 2006. Em contrapartida, 56 municípios registraram uma situação melhor do que a classificação de 2005, evidenciando uma redução da vulnerabilidade aos indicadores adotados.

\section{4 ÍNDICE MUNICIPAL DE ALERTA - IMA 2007}

No ano de 2007, verificou-se que 25 municípios encontravam-se na classe de Alta Vulnerabilidade do IMA, como visto na Figura 4, os quais estão localizados predominantemente nas Macrorregiões de Planejamento dos Sertões dos Inhamuns, Sertão Central, Sobral-Ibiapaba e Cariri/Centro Sul. Os cinco municípios que apresentaram os maiores valores do IMA em 2007 foram: Catunda $(0,801)$, Madalena $(0,787)$, Irauçuba $(0,767)$, Ipaumirim $(0,762)$ e Caridade $(0,761)$. Já os cinco municípios 


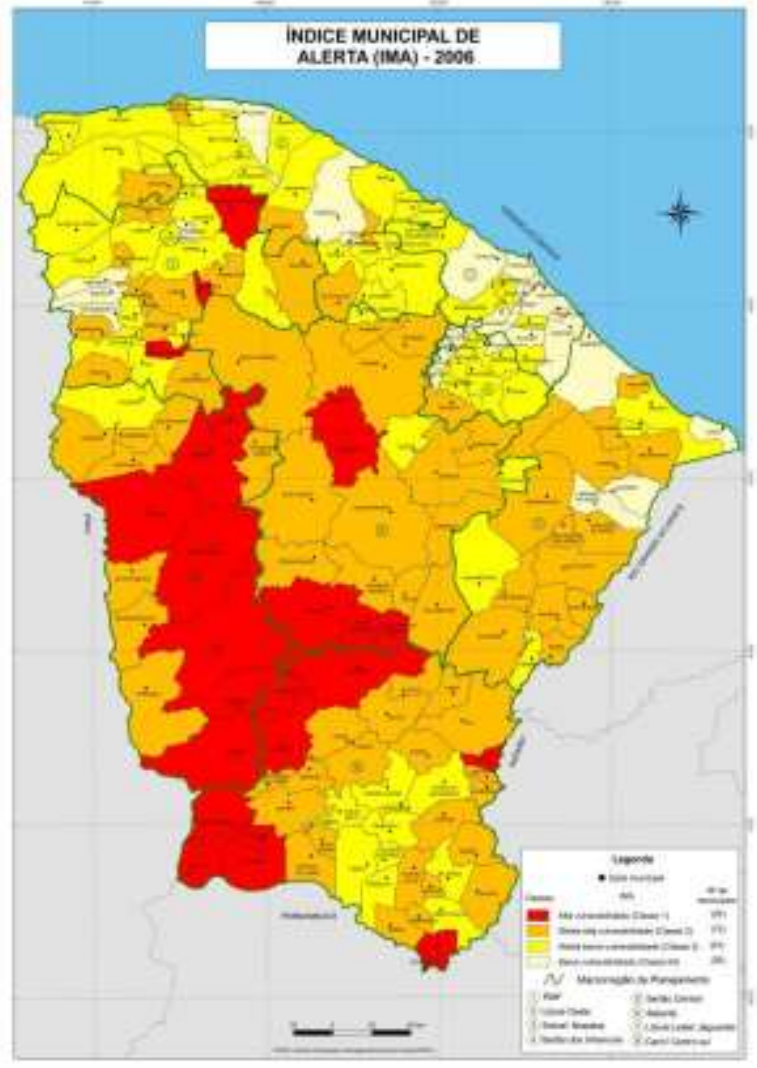

Figura 3. Índice Municipal de Alerta (IMA) - 2006. Fonte: IPECE (IMA - 2006)

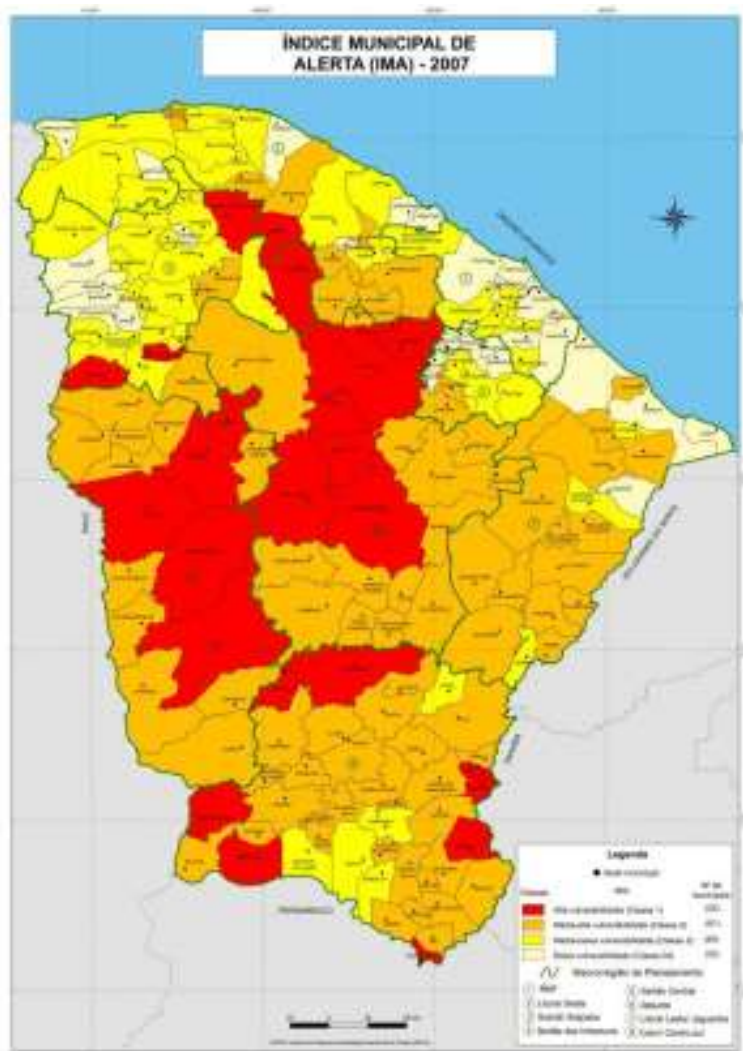

Figura 4. Índice Municipal de Alerta (IMA) - 2007. Fonte: IPECE (IMA - 2007)

menos vulneráveis aos fatores climatológicos e agrícolas no citado ano foram: Ibiapina $(0,354)$, Cascavel $(0,383)$, Fortaleza $(0,395)$, Pacoti $(0,401)$ e Meruoca $(0,403)$.

Analisando o ano de 2006, verificou-se que 34 municípios apresentaram piora na classificação do IMA, ou seja, foram classificados em uma classe de maior vulnerabilidade em 2007. Em contrapartida, 32 municípios registraram uma situação melhor do que a classificação de 2006, evidenciando uma redução da vulnerabilidade aos indicadores adotados.

\section{5 ÍNDICE MUNICIPAL DE ALERTA - IMA 2008}

No ano de 2008, observou-se que 35 municípios (Figura 5) encontravam-se na classe de Alta Vulnerabilidade do IMA, os quais estão localizados predominantemente nas Macrorregiões de Planejamento dos Sertões dos Inhamuns, Sertão Central, Sobral-Ibiapaba e Cariri/Centro Sul. Os cinco municípios que apresentaram os maiores valores do IMA em 2008 foram: Aiuaba $(0,714)$, Fortim $(0,711)$, Orós $(0,709)$, Madalena $(0,695)$ e Santa Quitéria $(0,694)$. Já os cinco municípios menos vulneráveis aos fatores climatológicos e agrícolas no citado ano foram: São Benedito $(0,361)$, Meruoca $(0,365)$, Ubajara $(0,372)$, Ibiapina $(0,402)$ e Aratuba $(0,448)$.

Comparando com o ano de 2007, registrou-se que 54 municípios apresentaram piora na classificação do IMA, ou seja, foram classificados em uma classe de maior vulnerabilidade em 2008. Em contrapartida, 31 municípios registraram uma situação melhor do que a classificação de 2007, evidenciando uma redução da vulnerabilidade quanto aos indicadores adotados.

\section{6 ÍNDICE MUNICIPAL DE ALERTA - IMA 2009}

No ano de 2009, constatou-se, conforme a Figura 6, que 37 municípios encontram-se na classe de Alta Vulnerabilidade do IMA, estando localizados predominantemente nas Macrorregiões de Planejamento dos Sertões dos Inhamuns, Sertão Central e Cariri/Centro Sul. Os cinco municípios que apresentaram os maiores valores do IMA em 2009 foram: Madalena $(0,824)$, Dep. Irapuan Pinheiro $(0,824)$, Arneiroz $(0,812)$, Santana do Acaraú $(0,803)$ e Penaforte $(0,800)$. Já os cinco municípios menos 
vulneráveis aos fatores climatológicos e agrícolas no citado ano foram: Meruoca $(0,427)$, Pacoti $(0,427)$, São Benedito $(0,445)$, Ibiapina $(0,0450)$ e Palmácia $(0,471)$.

Comparativamente ao ano de 2008, tem-se que 37 municípios apresentaram piora na classificação do IMA, ou seja, foram classificados em uma classe de maior vulnerabilidade em 2009. Em contrapartida, 56 municípios registraram melhor situação do que a classificação de 2008 , evidenciando redução da vulnerabilidade aos indicadores adotados.

\section{7 ÍNDICE MUNICIPAL DE ALERTA - IMA 2010}

No ano de 2010, de acordo com a Figura 7, constatou-se que 25 municípios encontram-se na classe de Alta Vulnerabilidade do IMA, estando localizados predominantemente nas Macrorregiões de Planejamento dos Sertões dos Inhamuns, Sertão Central, Sobral-Ibiapaba e Cariri/Centro Sul. Os cinco municípios que apresentaram os maiores valores do IMA em 2010 foram: Caridade $(0,835)$, Groaíras $(0,818)$, Crateús $(0,814)$, Irauçuba $(0,812)$ e Madalena $(0,808)$. Já os cinco municípios menos vulneráveis aos fatores climatológicos e agrícolas no citado ano foram: Ibiapina $(0,312)$, Itarema $(0,431)$, São Benedito $(0,439)$, Guaramiranga $(0,454)$ e Meruoca $(0,464)$.

Em relação ao ano de 2009, constatou-se que 41 municípios apresentaram piora na classificação do IMA, ou seja, foram classificados em uma classe de maior vulnerabilidade em 2010. Em contrapartida, 36 municípios registraram situação melhor do que a classificação de 2009, evidenciando redução da vulnerabilidade aos indicadores adotados.

\subsection{Análise e reflexões do IMA para o estado do Ceará entre os anos de 2004 a 2010.}

Apresenta-se nesta seção a análise do monitoramento do indicador do IMA para os municípios cearenses para o período de 2004 a 2010, procurando identificar os municípios mais vulneráveis, bem como os menos vulneráveis aos aspectos agrícolas e climatológicos. Dentre os resultados encontrados, chegamos à constatação que 22 municípios permaneceram sempre na mesma classe de vulnerabilidade do IMA entre os anos de 2004 a 2010, de onde partiremos para outras análises.

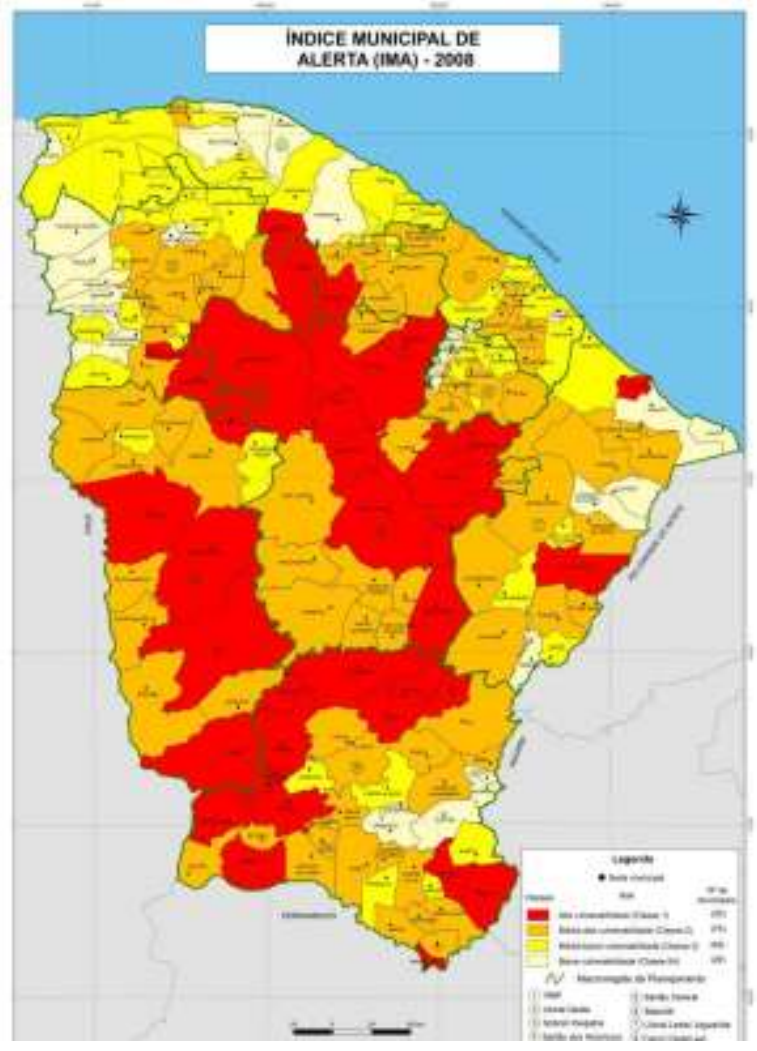

Figura 5. Índice Municipal de Alerta (IMA) - 2008. Fonte: IPECE (IMA - 2008)

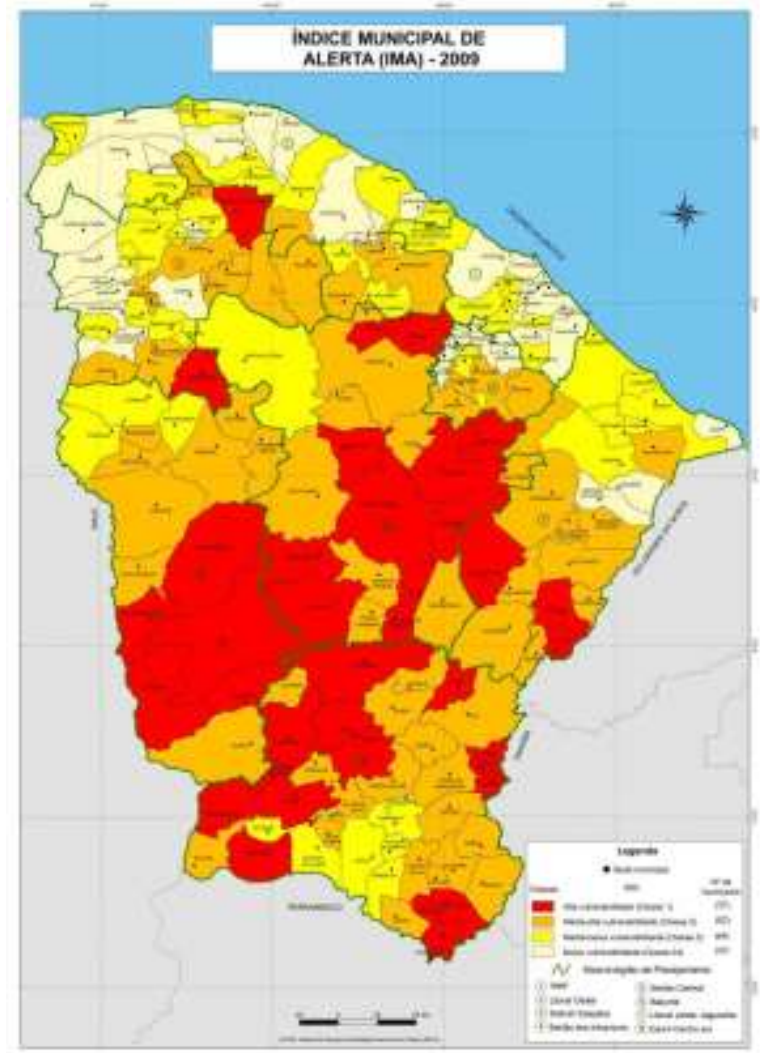

Figura 6. Índice Municipal de Alerta (IMA) - 2009.

Fonte: IPECE (IMA - 2009) 
$\mathrm{Na}$ classe 4, que representa baixa vulnerabilidade, observou-se que os seguintes municípios sempre estiveram presentes: Aratuba, Guaramiranga, Ibiapina, Meruoca, Mulungu, Pacoti, Palmácia, Quixeré, São Benedito e Ubajara, totalizando 10 municípios.

Podemos inferir a princípio que algumas características naturais e comuns a maioria desses municípios podem estar relacionadas ao resultado obtido no indicador de vulnerabilidade. Como principal característica observada entre os municípios ressalta-se a localização dos mesmos em termos de altitude, considerando que são municípios situados em serras e/ou planaltos, o que implica, conseqüentemente, em temperatura amena e nível de precipitação elevado, dentre outras características climáticas que favorecem a menor vulnerabilidade. No caso específico do município de Quixeré o mesmo possui uma agricultura bem desenvolvida, detendo perímetros irrigados com a utilização mais intensiva em tecnologia na produção, ou seja, apoiado pelo vetor do agronegócio em larga escala e com produção quase que exclusivamente destinado à exportação.

No Grupo 3, que representa média-baixa vulnerabilidade, observou-se que os municípios de Marco, Trairi e Varjota estão presentes durante todo o período.

Passando para os municípios que apresentam vulnerabilidades maiores, no Grupo 2, que representa média-alta vulnerabilidade, constata-se como invariantes nesse grupo os municípios de Icó, Ipaporanga, Jaguaribe, Senador Pompeu e Tabuleiro do Norte.

Por fim, figuram em todo o período do estudo dentre os municípios com maior vulnerabilidade (Grupo 1) os municípios de Independência, Madalena, Penaforte e Tauá. Estes municípios possuem como característica principal possuírem baixos índices pluviométricos, sendo também vulneráveis no tocante à produção agrícola.

A partir dos achados acima apresentados passamos à análise mais agregada, ou seja, analisamos os municípios que sempre estiveram em situação de menor vulnerabilidade, Grupos 4 e 3, e maior vulnerabilidade, Grupos 1 e 2.

Os municípios que sempre estiveram nas classes de Média-Baixa Vulnerabilidade e Baixa Vulnerabilidade no período compreendido entre os anos de 2004 a 2010 foram: Acarape, Acaraú, Alcântaras,

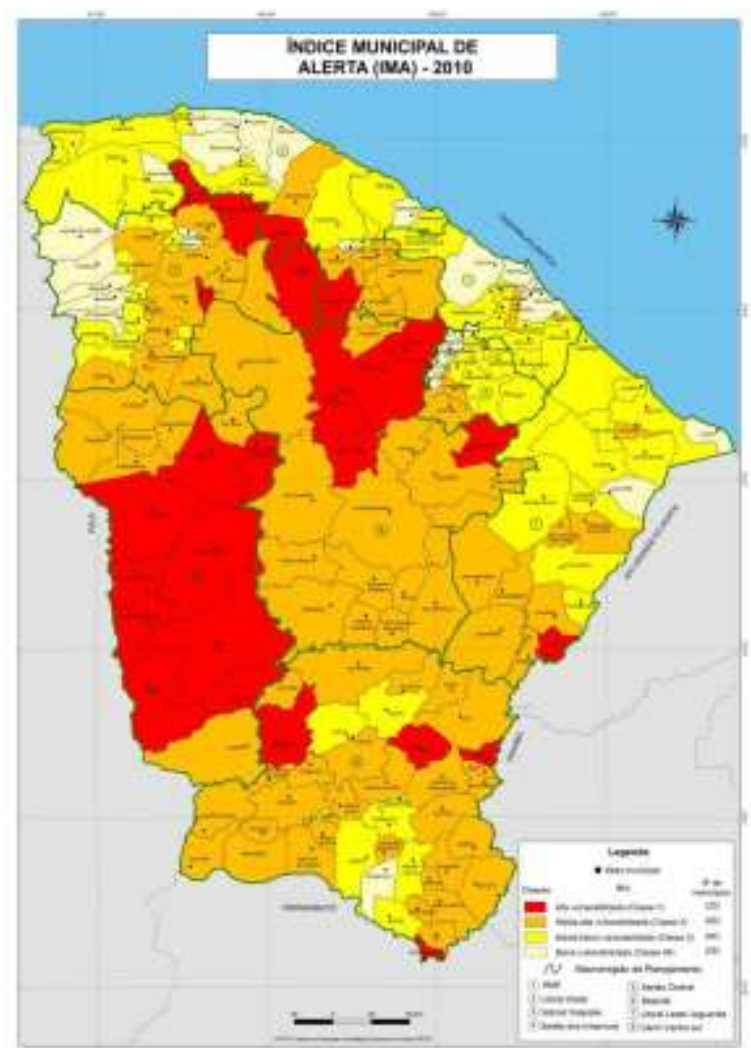

Figura 7. Índice Municipal de Alerta (IMA) - 2010. Fonte: IPECE (IMA - 2010)

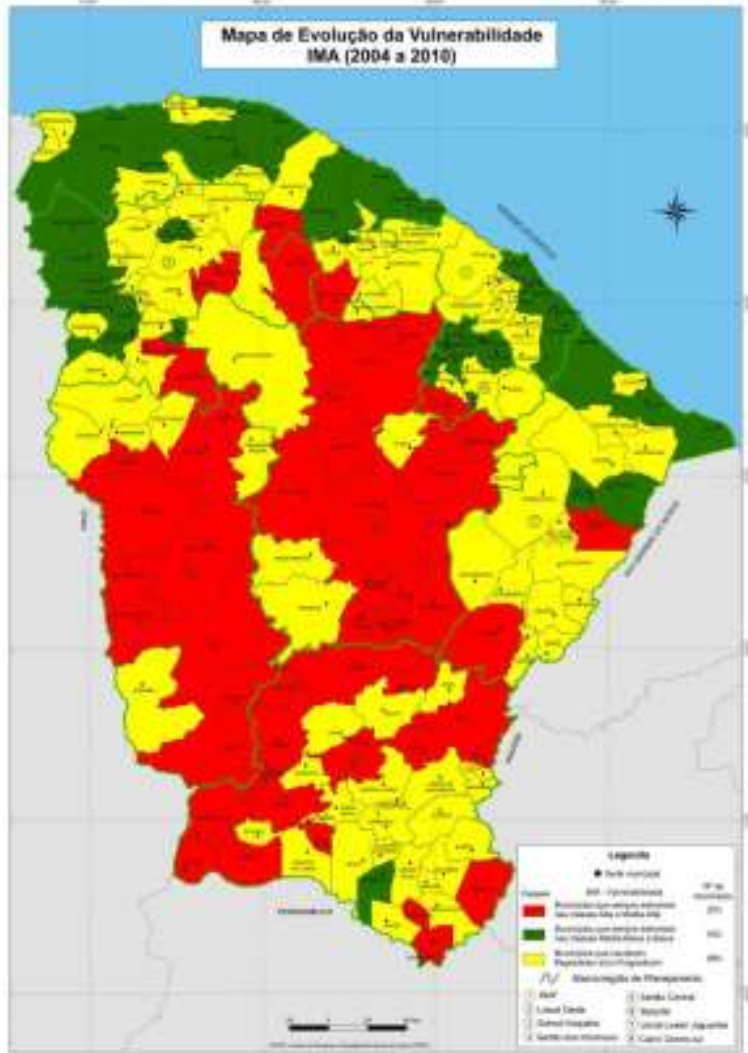

Figura 8. Evolução da Vulnerabilidade do IMA - 2004 a 2010. Fonte: IPECE (IMA - 2004/2010) 
Aquiraz, Aracati, Aratuba, Barbalha, Barreira, Baturité, Beberibe, Bela Cruz, Camocim, Cascavel, Eusébio, Fortaleza, Graça, Granja, Guaraciaba do Norte, Guaramiranga, Ibiapina, Icapuí, Itapipoca, Itarema, Limoeiro do Norte, Marco, Martinópole, Meruoca, Mulungu, Pacoti, Palmácia, Paracuru, Paraipaba, Pindoretama, Quixeré, Redenção, São Benedito, Tianguá, Trairi, Ubajara, Uruburetama, Varjota e Viçosa do Ceará, perfazendo um total de 42 municípios.

Por outro lado os municípios cearenses que sempre estiveram nas classes de Alta Vulnerabilidade e Média-Alta Vulnerabilidade no período compreendido entre os anos de 2004 a 2010 totalizam 53 municípios, sendo os mesmos Acopiara, Aiuaba, Antonina do Norte, Araripe, Arneiroz, Assaré, Banabuiú, Boa Viagem, Campos Sales, Canindé, Caridade, Cariús, Catarina, Catunda, Cedro, Crateús, Deputado Irapuan Pinheiro, Forquilha, Groaíras, Hidrolândia, Ibaretama, Icó, Independência, Ipaporanga, Irauçuba, Itapiúna, Itatira, Jaguaribe, Jati, Madalena, Mauriti, Milha, Miraíma, Nova Olinda, Novo Oriente, Paramoti, Penaforte, Piquet Carneiro, Pires Ferreira, Porteiras, Quiterianópolis, Quixadá, Quixelô, Quixeramobim, Saboeiro, Salitre, Senador Pompeu, Solonópoles, Tabuleiro do Norte, Tamboril, Tauá, Tejuçuoca e Umari.

Avaliando a mobilidade dos municípios entre as classes de vulnerabilidades, saindo de uma situação de alta vulnerabilidade para uma de baixa vulnerabilidade, ou o contrário, constatamos a efetiva possibilidade de mudança na situação de vulnerabilidade, sempre levando em consideração que as posições são relativas e que as mudanças estão relacionadas com as mudanças ocorridas nos outros municípios. Observou-se que 89 municípios regrediram e/ou progrediram os seus graus de vulnerabilidade durante o período de 2004 a 2010. A Figura 8 mostra uma visão territorial da evolução dos municípios quanto a vulnerabilidade do IMA entre os anos de 2004 e 2010.

\section{CONCLUSÕES}

Os prejuízos econômicos e sociais na Região Nordeste, e especificamente no Estado do Ceará, decorrentes de secas e instabilidades climáticas incluem perdas de lavouras, desabastecimento de água, desemprego e fome, expondo a população rural às mais diversas vulnerabilidades.

A irregularidade na distribuição temporal e espacial das chuvas compromete o desempenho da agricultura e o acúmulo de água nos reservatórios, os quais constituem fatores de desagregação social e econômico das famílias de trabalhadores rurais dos municípios, levando à vulnerabilidade social diante da insatisfação das necessidades básicas. Isso se justifica se considerarmos que a renda dos trabalhadores rurais é predominantemente proveniente da produção de sequeiro, como o milho, o arroz, o feijão e a mandioca, altamente susceptíveis à falta de água. Dessa forma, os produtores, via de regra, têm pequena capacidade de poupança e suas reservas suprem, quando possível, apenas as necessidades básicas de sobrevivência por um curto período de tempo. Deve-se considerar que os programas de transferência de renda adotados no País nos últimos anos parecem ter mitigado a situação de vulnerabilidade dessas populações, no entanto, esse fato não é tema desse estudo.

Diante disso, torna-se necessária uma ação eficaz e imediata por parte do setor público e da sociedade organizada nos municípios que apresentam situação de vulnerabilidade, de acordo com o Índice Municipal de Alerta - IMA, calculado pelo IPECE. Dentre os municípios nessa situação a ênfase deve ser para aqueles municípios que ao longo do tempo sempre permaneceram na classe de maior vulnerabilidade: Independência, Madalena, Penaforte e Tauá, observando em que aspectos esses municípios apresentam maior vulnerabilidade, de acordo com as variáveis do IMA.

O mesmo exercício deve ser feito para os municípios que permaneceram durante todo o período na classe de média-alta vulnerabilidade: Icó, Ipaporanga, Jaguaribe, Senador Pompeu e Tabuleiro do Norte. A partir daí, deve-se estabelecer prioridades dentre os municípios que flutuaram nas classes de Alta vulnerabilidade e média-alta vulnerabilidade, com políticas públicas e ações que possam reduzir a situação de vulnerabilidade dos mesmos.

Vale destacar que os impactos sociais normalmente se manifestam na perda da capacidade produtiva dos grupos familiares, a qual, se tratando das populações sertanejas submetidas à pobreza quase absoluta e a uma estrutura fundiária injusta, tende a acentuar os movimentos migratórios. 


\section{REFERÊNCIAS}

BURROUGH, P.A. (1987). Principles of geographical information systems for land resources assessment. Oxford: Claredon Press, 193p.

GOVERNO DO ESTADO DO CEARÁ (1998). Diagnóstico e Macrozoneamento Ambiental do Estado do Ceará: Diagnóstico Geoambiental. v.1. Fortaleza: Convênio FCPC/Semace, 256p.

INSTITUTO DE PESQUISA E ESTRATÉGIA ECONÔMICA DO CEARÁ (IPECE) (Ceará). Índice Municipal de Alerta-IMA 2004. Disponível em: <http://www.ipece.ce.gov.br>. Acesso em: 27 dez. 2013.

INSTITUTO DE PESQUISA E ESTRATÉGIA ECONÔMICA DO CEARÁ (IPECE) (Ceará). Índice Municipal de Alerta-IMA 2005. Disponível em: <http://www.ipece.ce.gov.br>. Acesso em: 27 dez. 2013.

INSTITUTO DE PESQUISA E ESTRATÉGIA ECONÔMICA DO CEARÁ (IPECE) (Ceará). Índice Municipal de Alerta-IMA 2006. Disponível em: <http://www.ipece.ce.gov.br>. Acesso em: 27 dez. 2013.

INSTITUTO DE PESQUISA E ESTRATÉGIA ECONÔMICA DO CEARÁ (IPECE) (Ceará). Índice Municipal de Alerta-IMA 2007. Disponível em: <http://www.ipece.ce.gov.br>. Acesso em: 27 dez. 2013.

INSTITUTO DE PESQUISA E ESTRATÉGIA ECONÔMICA DO CEARÁ (IPECE) (Ceará). Índice Municipal de Alerta-IMA 2008. Disponível em: <http://www.ipece.ce.gov.br>. Acesso em: 27 dez. 2013.

INSTITUTO DE PESQUISA E ESTRATÉGIA ECONÔMICA DO CEARÁ (IPECE) (Ceará). Índice Municipal de Alerta-IMA 2009. Disponível em: <http://www.ipece.ce.gov.br>. Acesso em: $27 \mathrm{dez} .2013$.

INSTITUTO DE PESQUISA E ESTRATÉGIA ECONÔMICA DO CEARÁ (IPECE) (Ceará). Índice Municipal de Alerta-IMA 2010. Disponível em: <http://www.ipece.ce.gov.br>. Acesso em: 27 dez. 2013.

FLORENZANO, T.G. (2007). Iniciação em Sensoriamento Remoto. São Paulo: Oficina de Textos, 128p.

FRANÇA, Á.E.D.; ACCIOLY, L.J.O.; OLIVEIRA, A.K.C. (2002). Reflexos da Desertificação no Nordeste do Brasil. Recife: Embrapa Solos UEP, 5p.

LEITE, F.R.B.; OLIVEIRA, S.B.P.; BARRETO, M.M.S.; CARVALHO, G.M.B.S; FILHO, M.R.F. (2003). Degradação Ambiental e Susceptibilidade aos Processos de Desertificação na Região do Médio Jaguaribe- CE. Anais XI SBSR, Belo Horizonte, Brasil, p. 1315 - 1322.

MEDEIROS, C.N.; ARAGÃO, M.C.A.; GOMES, D.D.M; ALBUQUERQUE, E.L.S. (2013). Utilização de software livre para disponibilização de dados georreferenciados na internet: caso do sistema Ceará em mapas interativo. Revista Brasileira de Cartografia, v. 65, p.25-34.

MINISTÉRIO DO MEIO AMBIENTE (MMA) (BRASIL) (2010). PAE - Programa de Ação Estadual de Combate à Desertificação. Fortaleza: Ministério do Meio Ambiente. Secretaria dos Recursos Hídricos, 372p.

SOUZA, M.J.N.; LIMA, L.C.; MORAES, J.O. (2000). Compartimentação Territorial e Gestão Regional do Ceará. Fortaleza: ed. Funece, 268p. 